\title{
The efficacy of sentinel lymph node mapping with indocyanine green in cervical cancer
}

Ju-Hyun Kim, Dae-Yeon Kim *iD, Dae-Shik Suh, Jong-Hyeok Kim, Yong-Man Kim, Young-Tak Kim and Joo-Hyun Nam

\begin{abstract}
Background: Lymph node metastasis is a significant predictive factor for disease recurrence and survival in cervical cancer patients. Given the importance of lymph node metastasis, it is imperative that patients harboring metastasis are identified and can undergo appropriate treatment. Sentinel lymph node (SLN) mapping has drawn attention as a lymph node mapping technique. We evaluated the feasibility and efficacy of (SLN) mapping using indocyanine green (ICG) in cervical cancer.
\end{abstract}

Methods: We performed a single-center, retrospective study of 103 surgically treated cervical cancer patients who underwent SLN mapping. After using ICG to detect SLN during surgery, we removed the SLNs followed by laparoscopic or robotic-assisted radical surgery and bilateral pelvic lymphadenectomy.

Results: Stage IB1 was the most common (61.17\%). At least one SLN was detected in all cases. Eighty-eight patients (85.44\%) had bilateral pelvic SLNs. The mean number of SLN per patient was 2.34. The side-specific sensitivity was $71.43 \%$, the specificity was $100 \%$, the negative predictive value (NPV) was $93.98 \%$, and the false negative rate (FNR) was $28.57 \%$. In cases of tumors smaller than $2 \mathrm{~cm}$ with negative lymph node metastasis on imaging, the study revealed a side-specific sensitivity of $100 \%$, a specificity of $100 \%$, a NPV of $100 \%$, and a FNR of $0 \%$. Large tumor size $(\geq 4 \mathrm{~cm})$, a previous history of a loop electrosurgical excision procedure (LEEP), depth of invasion ( $\geq 50 \%$ ), the microscopic parametrial (PM) invasion, and vaginal extension were significantly associated with the false-negative detection of SLN. Moreover, the microscopic PM invasion was the only risk factor of the false-negative detection of SLN in multivariate analysis.

Conclusion: SLN mapping with ICG in cervical cancer is feasible and has high detection rate. The sensitivity of 100\% was high enough to perform SLN biopsy alone in an early stage in which the tumor is less than $2 \mathrm{~cm}$, with no lymphadenopathy on image examination. However, for large or invasive tumors, we would have to be cautious about performing SLN biopsy alone.

Trial registration: Retrospectively registered 2017-0600.

Keywords: Sentinel lymph node, Indocyanine green, Sensitivity and specificity, Detection, Uterine cervical neoplasms

\footnotetext{
*Correspondence: kdyog@amc.seoul.kr

Department of Obstetrics and Gynecology, University of Ulsan College of

Medicine, Asan Medical Center, 88 Olympic-ro, 43-gil, Songpa-gu, Seoul

05505, Republic of Korea
} 


\section{Background}

According to the American Cancer Society, in 2016, an estimated 12,900 cervical cancer patients were newly diagnosed in the USA, and about 4100 people died of cervical cancer [1]. In Korea, there is a much higher incidence of cervical cancer compared with the West, although it has decreased gradually in the past few decades [2, 3]. Despite the fact that the present International Federation of Gynecology and Obstetrics (FIGO) staging system does not include lymph node metastasis in cervical cancer, lymph node metastasis is the most significant predictive factor for recurrence and survival in surgically treated cervical cancer patients [4-6]. It is known that approximately $20 \%$ of early cervical cancer patients have pelvic lymph node metastasis [7, 8]. If lymph node metastasis is found, the 5-year survival rate decreases from 92 to $64 \%[9,10]$.

The standard surgical procedure for early cervical cancer includes pelvic lymphadenectomy [11]. The complications and morbidities arising from complete pelvic lymph node dissection, such as lymphocele and lymphedema, can be substantial problems in these patients [12]. Considering the status of lymph node metastasis, many patients may be undergoing unnecessary pelvic lymph node dissection and suffering from the resulting complications [13, 14]. Therefore, nodal assessment techniques, such as sentinel lymph node (SLN) mapping, are receiving much attention.

The SLN may be defined as the first regional lymph node or group of lymph nodes into which cancer cells are excreted from the primary tumor and invade during metastasis [15]. The detection of SLN in breast, penile, and skin cancer is a standard diagnostic procedure. If an SLN tests negative for cancer, full lymph node dissection can be omitted [16-18]. Several recent studies have proven the overall satisfactory efficacy of SLN biopsy in endometrial and cervical cancer $[19,20]$. In early cervical cancer, the majority of studies of SLN biopsy have shown a detection rate of $95-100 \%$, a false-negative rate (FNR) of $0-8 \%$, and a negative predictive value (NPV) of 97-100\% [21]. Despite these good results, there is still controversy because of the relatively high FNR in patients with large cervical cancers [11, 22-24].

In Korea, radical hysterectomy is preferred in the initial treatment of cervical cancer up to stages IB2 and IIA [25]. However, SLN biopsy is not widely used. In our center (Asan Medical Center, Korea), we have performed a retrospective review of SLN biopsy in cervical cancer. Our purpose was to determine the feasibility and efficacy of SLN mapping using indocyanine green (ICG) in patients with cervical cancer.

\section{Methods}

\section{Study design and patient eligibility}

We have performed a single-center, retrospective study of surgically treated cervical cancer patients with SLN mapping from August 2015 to January 2017 at Asan Medical Center, Korea. According to gynecologic oncologists' judgments, patients over 18 years old who were pathologically diagnosed with cervical cancer and underwent surgical treatment were eligible for this study. International Federation of Gynecology and Obstetrics (FIGO) stage IA1 with lymphovascular space invasion (LVSI) to IIA disease was included, and preoperative magnetic resonance imaging (MRI) and $18 \mathrm{~F}$-fluorodeoxyglucose positron emission tomography/computed tomography (18F-FDG PET/CT) were performed in all patients to exclude distant metastasis. Moreover, patients with a history of pelvic radiation therapy were excluded. Study approval was obtained from the institutional review board of Asan Medical Center, and all patients provided their informed consent. Study eligibility required surgery, including robotic-assisted or laparoscopicassisted radical hysterectomy, trachelectomy with SLN mapping, and pelvic lymph node dissection. Five gynecologic oncologists performed the SLN mapping.

\section{Indocyanine green injection and surgical procedure}

We selected ICG for SLN evaluation. A 25-mg single vial was used at each surgery. ICG was diluted with $20 \mathrm{ml}$ of normal saline. Therefore, $1.25 \mathrm{mg} / \mathrm{ml}$ of ICG was used. After general anesthesia and just before placing the uterine manipulator, a total of $4 \mathrm{ml}$ of ICG was injected directly to the right and left of the uterine cervix, both superficially and deep into the stroma. A fluorescence camera was used to identify the SLN with the retroperitoneum assessed. Only the SLN mapping technique was used. After the detection of SLNs, we removed and submitted them for frozen biopsy in case of suspicious metastasis. Followed by radical surgery, complete bilateral pelvic lymphadenectomy was performed in all patients. Moreover, some surgeons performed paraaortic lymph node dissection to the inferior mesenteric artery level if there was a metastasis of pelvic SLNs.

\section{Histopathology evaluation}

Pathologists who specialized in gynecologic pathology examined all surgical specimens. The frozen biopsy was performed during operation. The result of SLN biopsy was obtained using ultrastaging, which was conducted in the same manner as for breast cancer [26]. Cytokeratin immunohistochemical staining was performed to check whether the lymph node was affected by metastasis. Hematoxylin-eosin staining was performed by dividing the specimen in half in case that it was not an SLN.

\section{Statistics}

We collected all data from medical records. The descriptive statistics were used to analyze the demographic and 
clinical information and SLN mapping characteristics. Information such as sensitivity, specificity, NPV, and FNR was calculated as per patient and per hemipelvis to analyze the performance of SLN. We calculated the 95\% confidence intervals for these rates using the exact binomial method.

We defined the false-negative detection of SLN as when the results of SLN biopsy was negative, but the result of none-SLN biopsy in the same side was positive for metastasis. The patients were divided into two groups depending on performance to find out the factors that influenced the false-negative detection of SLN. One group is a good performance group of no false-negative detection of SLN with bilaterality. Another group is a bad performance group of false-negative detection of SLN. And the two groups were analyzed using Fisher's exact test. We also performed univariate and multivariate logistic regression of the risk factors affecting falsenegative detection of SLN. For multivariable logistic regression, the stepwise variable selection was performed by backward elimination as final variables. All data were analyzed using SPSS software (version 21.0; SPSS Inc., Chicago, IL).

\section{Results}

From August 2015 to January 2017, 103 cervical cancer patients were surgically treated with SLN mapping using ICG at Asan Medical Center. The demographic and clinical information of the patients is summarized in Table 1. The median patient age was 45 years (range, $29-77$ years). The median body mass index was $22.42 \mathrm{~kg} / \mathrm{m}^{2}$ (range, $\left.17.99-29.89 \mathrm{~kg} / \mathrm{m}^{2}\right)$, and the median parity was $2(42.7 \%$, range $0-5)$. Stage IB1 disease was the most common (61.17\%), followed by stage IB2 (19.42\%). Forty-eight patients $(46.60 \%)$ had undergone previous LEEP. The most common surgery was a laparoscopic radical hysterectomy (45.73\%) followed by robotic-assisted radical hysterectomy (39.81\%). Eight patients (7.77\%) underwent fertilitysparing surgery.

The pathologic information is shown in Table 2. The most common histologic type was squamous cell carcinoma $(n=72,69.90 \%)$, followed by adenocarcinoma $(n=23,22.33 \%)$. The median tumor size based on the pathologic report was $2.4 \mathrm{~cm}$ (range, $0.1-8 \mathrm{~cm}$ ). Twenty-five patients (24.27\%) had large tumors of more than $4 \mathrm{~cm}$, and 35 patients (33.98\%) had LVSI. One patient had resection margin involvement. Moreover, the tumors of 11 patients (10.68\%) extended into the vagina. The DOI of 55 patients (53.40\%) was more than $50 \%$. Nineteen patients (18.45\%) had PM invasion, and 27 patients $(26.2 \%)$ had nodal metastasis after lymphadenectomy on the final pathologic report.

Table 3 shows the characteristics of SLN mapping. At least 1 SLN was detected in all cases. Eighty-eight patients
Table 1 Demographic and clinical information $(n=103)$

\begin{tabular}{|c|c|c|}
\hline Characteristics & Values & Percentage (\%) \\
\hline \multicolumn{3}{|l|}{ Age (years) } \\
\hline Median (range) & $45(29-77)$ & \\
\hline \multicolumn{3}{|c|}{ Body mass index $\left(\mathrm{kg} / \mathrm{m}^{2}\right)$} \\
\hline Median (range) & $22.42(17.99-29.89)$ & \\
\hline \multicolumn{3}{|l|}{ Parity $(n)$} \\
\hline 0 & 20 & 19.42 \\
\hline 1 & 17 & 16.5 \\
\hline 2 & 44 & 42.72 \\
\hline 3 & 17 & 16.5 \\
\hline$\geq 4$ & 5 & 4.85 \\
\hline \multicolumn{3}{|c|}{ Surgical procedure $(n)$} \\
\hline RARH & 41 & 39.81 \\
\hline RAMRH & 3 & 2.91 \\
\hline RART & 1 & 0.97 \\
\hline LARH & 47 & 45.73 \\
\hline LAMRH & 4 & 3.88 \\
\hline LART & 7 & 6.8 \\
\hline \multicolumn{3}{|c|}{ Previous LEEP history $(n)$} \\
\hline No & 55 & 53.4 \\
\hline Yes & 48 & 46.6 \\
\hline \multicolumn{3}{|l|}{ HPV infection (n) } \\
\hline No & 6 & 5.82 \\
\hline Yes & 65 & 63.11 \\
\hline Unknown & 32 & 31.07 \\
\hline \multicolumn{3}{|l|}{ FIGO stage $(n)$} \\
\hline $\mid \mathrm{A} 1$ & 8 & 7.77 \\
\hline IA2 & 6 & 5.83 \\
\hline |B1 & 63 & 61.17 \\
\hline IB2 & 20 & 19.42 \\
\hline$\| A$ & 6 & 5.83 \\
\hline
\end{tabular}

LEEP loop electrosurgical excision procedure, HPV human papillomavirus, FIGO International Federation of Obstetrics and Gynecology, RARH robotic-assisted radical hysterectomy, $R A M R H$ robotic-assisted modified radical hysterectomy, RART robotic-assisted radical trachelectomy, LARH laparoscopic-assisted radical hysterectomy, LAMRH laparoscopic-assisted modified radical hysterectomy, LART laparoscopic-assisted radical trachelectomy

(85.44\%) had bilateral pelvic SLNs. The mean number of SLNs per patient was 2.34. The most common SLN was the obturator lymph node (54.36\%) followed by the external iliac lymph node $(34.85 \%)$. One patient had a para-aortic SLN. The SLN was the only positive node in 10 patients (9.7\%) of total patients. Four patients had lymph node metastasis on one side that were not detected as an SLN.

Calculated on a per patient basis, the sensitivity of SLN biopsy was $76.92 \%$ (95\% CI $57.95-88.97 \%$ ), the sensitivity was $100 \%$ (95\% CI $95.00-100 \%$ ), the FNR was $23.08 \%$, and the NPV was $92.41 \%$ (95\% CI 84.40-96.47\%). 
Table 2 Pathologic information $(n=103)$

\begin{tabular}{|c|c|c|}
\hline Characteristics & Values & Percentage (\%) \\
\hline \multicolumn{3}{|l|}{ Histologic type $(n)$} \\
\hline Squamous cell carcinoma & 72 & 69.9 \\
\hline Endometrioid adenocarcinoma & 1 & 0.97 \\
\hline Adenocarcinoma & 23 & 22.33 \\
\hline Adenosquamous cell carcinoma & 4 & 3.88 \\
\hline Other types & 3 & 2.91 \\
\hline \multicolumn{3}{|l|}{ Grade $(n)$} \\
\hline Well differentiated & 9 & 8.74 \\
\hline Moderately differentiated & 72 & 69.9 \\
\hline Poorly differentiated & 15 & 14.56 \\
\hline Unknown & 7 & 6.8 \\
\hline \multicolumn{3}{|l|}{ Tumor size $(\mathrm{cm})$} \\
\hline Median (range) & $2.4(0.1-8)$ & \\
\hline \multicolumn{3}{|l|}{ (n) } \\
\hline$<4 \mathrm{~cm}$ & 78 & 75.73 \\
\hline$\geq 4 \mathrm{~cm}$ & 25 & 24.27 \\
\hline \multicolumn{3}{|l|}{ Presence of LVSI (n) } \\
\hline No & 68 & 66.02 \\
\hline Yes & 35 & 33.98 \\
\hline \multicolumn{3}{|l|}{ Resection margin involvement $(n)$} \\
\hline No & 102 & 99.03 \\
\hline Yes & 1 & 0.97 \\
\hline \multicolumn{3}{|l|}{ Vaginal extension ( $n$ ) } \\
\hline No & 92 & 89.32 \\
\hline Yes & 11 & 10.68 \\
\hline \multicolumn{3}{|l|}{ Depth of invasion (n) } \\
\hline$<1 / 2$ & 48 & 46.6 \\
\hline$\geq 1 / 2$ & 55 & 53.4 \\
\hline \multicolumn{3}{|l|}{ Parametrial invasion $(n)$} \\
\hline No & 84 & 81.55 \\
\hline Yes & 19 & 18.45 \\
\hline \multicolumn{3}{|l|}{ Lymph node metastasis } \\
\hline No & 76 & 73.79 \\
\hline Yes & 27 & 26.21 \\
\hline
\end{tabular}

LVSI lymphovascular invasion

At least one SLN was detected in 191 out of 206 hemipelvises; the side-specific SLN detection rate was $92.72 \%$. A total of 35 hemipelvises had lymph node metastasis, 25 of which involved the SLN, resulting in a sensitivity of $71.43 \%$ (95\% CI 54.95-83.67\%) and an FNR of $28.57 \%$. One hundred and fifty-six hemipelvises had negative lymph node metastasis, and all of them had negative SLNs, resulting in a specificity of $100 \%$ (95\% CI 97.60-100\%) and an NPV of 93.98\% (95\% CI 89.27$96.70 \%)$. For tumors less than $2 \mathrm{~cm}$ with no
Table 3 SLN mapping characteristics ( $n=103$, SLN $n=241)$

\begin{tabular}{lll}
\hline Variable & Value & $\%$ \\
\hline Mean number of SLN removed per patient $(n)$ & 2.34 & \\
SLN detention rate $(n)$ & & \\
$\quad$ Overall & 103 & 100 \\
Bilateral & 88 & 85.44 \\
Not mapping & 0 & 0 \\
SLN location ( $n)$ & & \\
External iliac & 84 & 34.85 \\
Obturator & 131 & 54.36 \\
Common iliac & 6 & 2.49 \\
Internal iliac & 9 & 3.73 \\
Parametrial & 9 & 3.73 \\
Paraaortic & 1 & 0.41 \\
Prescral & 1 & 0.41 \\
\hline SLN sentinel lymph node mapping & &
\end{tabular}

lymphadenopathy on imaging tests, the study revealed a sensitivity of $100 \%$ (95\% CI 20.65-100\%), a specificity of $100 \%$ (95\% CI $94.42-100 \%)$, and an NPV of 100\% (95\% CI 94.42-100\%) in terms of side-specificity (Table 4).

False-negative detection of SLN occurred in nine patients. The patients were divided into two groups depending on their performance. Tumor size $(P=0.0019)$, microscopic PM invasion $(P<0.0001)$, depth of invasion (DOI) $(P=0.003)$, a previous history of a loop electrosurgical excision procedure (LEEP) $(P=0.0339)$, and vaginal extension status $(P=0.0415)$ were associated with false-negative detection of SLN using Fisher's exact test (Table 5).

Also, we performed univariable logistic regression of the risk factors affecting false-negative detection of SLN, and the results are shown in Table 6 . The results of the univariate analysis revealed that the risk factors were tumor size of more than $4 \mathrm{~cm}$ (odds ratio (OR) 8.125, 95\% confidence interval (CI) 1.831-36.049; $P=0.0059$ ), LVSI (OR 8.674, 95\% CI 1.675-44.911; $P=0.01$ ), and microscopic PM invasion (OR 16.001, 95\% CI 3.398$75.35 ; P=0.0005)$. For the multivariate analysis, the variable selection was performed by backward elimination as final variables. Finally, the microscopic PM invasion was the only selected one as a final variable for the falsenegative detection of SLN.

\section{Discussion}

Our study was conducted on 103 cervical cancer patients who underwent SLN biopsy using ICG. The detection rate of SLN using ICG was $100 \%$, and the bilateral detection rate was $85.44 \%$. Our study showed improved detection rates over the previous traditional radiocolloid/blue dye mapping procedure [27]. The ICG mapping technique has more advantages, including 
Table 4 Performance of SLN mapping defined as side-specific

\begin{tabular}{lll}
\hline & $\begin{array}{l}\text { All, } n=103, \text { hemipelvis } \\
n=191\end{array}$ & $\begin{array}{l}n=36, \text { hemipelvis } n=66 \\
\text { Tumor size }<2 \mathrm{~cm} \text {, negative lymph node metastasis on } \\
\text { MRI and 18F-FDG PET/CT }\end{array}$ \\
\hline $\begin{array}{l}\text { Side-specific } \\
\text { detection } \\
\text { rate (\%) }\end{array}$ & 92.72 & $91.70 \%$ \\
$\begin{array}{l}\text { Sensitivity (\%, 95\% Cl) } \\
\text { Specificity (\%,95\% Cl) }\end{array}$ & \\
FNR (\%) & $71.43(54.95-83.67)$ & $100(20.65-100)$ \\
FPR (\%) & $100(97.60-100)$ & $100(94.42-100)$ \\
NPV (\%, 95\% Cl) & 28.57 & 0 \\
Accuracy (\%) & 0 & 0 \\
\hline
\end{tabular}

SLN sentinel lymph node mapping, FNR false-negative rate, FPR false-positive rate, $N P V$ negative predictive value

avoidance of radiation exposure, no pain, and a much lower cost than other traditional techniques [27]. According to a study of SLN mapping with ICG by Beavis et al., at least 1 SLN was detected in all cases

Table 5 Factors associated with false-negative detection of SLN

\begin{tabular}{|c|c|c|c|}
\hline Factors & Group 1, n (\%) & Group 2,n (\%) & $P$ value \\
\hline \multicolumn{4}{|c|}{ Tumor size } \\
\hline$<4 \mathrm{~cm}$ & $65(80.25)$ & $3(33.33)$ & \multirow[t]{2}{*}{0.0019} \\
\hline$\geq 4 \mathrm{~cm}$ & $16(19.75)$ & $6(66.67)$ & \\
\hline \multicolumn{4}{|c|}{ Previous LEEP } \\
\hline No & $39(48.15)$ & $1(11.11)$ & \multirow[t]{2}{*}{0.0339} \\
\hline Yes & $42(51.85)$ & $8(88.89)$ & \\
\hline \multicolumn{4}{|c|}{ Parametrium invasion } \\
\hline No & $72(88.89)$ & $3(33.33)$ & \multirow[t]{2}{*}{$<0.0001$} \\
\hline Yes & $9(11.11)$ & $6(66.67)$ & \\
\hline \multicolumn{4}{|c|}{ Depth of invasion } \\
\hline$<50 \%$ & $42(51.85)$ & $0(0)$ & \multirow[t]{2}{*}{0.003} \\
\hline$\geq 50 \%$ & $39(48.15)$ & $9(100)$ & \\
\hline \multicolumn{4}{|c|}{ Vagina extension } \\
\hline No & $73(90.12)$ & $6(66.67)$ & \multirow[t]{2}{*}{0.0415} \\
\hline Yes & $8(9.88)$ & $3(33.33)$ & \\
\hline \multicolumn{4}{|c|}{ Resention margin involvement } \\
\hline NO & $80(98.77)$ & $9(100)$ & \multirow[t]{2}{*}{$>0.999$} \\
\hline Yes & $1(1.23)$ & 0 & \\
\hline \multicolumn{4}{|c|}{ FIGO staging } \\
\hline $\mid A 1$ & $6(7.41)$ & 0 & \multirow[t]{5}{*}{0.5493} \\
\hline IA2 & $6(7.41)$ & 0 & \\
\hline IB1 & $51(62.96)$ & $5(55.56)$ & \\
\hline IB2 & $13(14.28)$ & $3(33.33)$ & \\
\hline$\| \mathrm{A}$ & $5(6.17)$ & $1(11.11)$ & \\
\hline
\end{tabular}

SLN sentinel lymph node mapping; LEEP loop electrosurgical excision procedure; FIGO International Federation of Obstetrics and Gynecology; Group 1, no false-negative detection group of sentinel lymph node with bilateral detection of sentinel lymph node; Group 2, false-negative detection group of sentinel lymph node and the bilateral detection rate of SLN was 87\% [28]. Similarly, we showed the feasibility of using ICG and its high detection rate.

In all cases, the sensitivity per hemipelvis was $71.43 \%$ (95\% CI 54.95-83.67\%), while the FNR was $28.57 \%$. There were nine cases of false-negative SLN detection. These are much less sensitive than the rates reported in a recent meta-analysis study and the SENTOCOL study $[20,29]$. Our patients had more advanced disease stages and larger tumors than these studies. Therefore, we additionally analyzed the factors affecting the false-negative detection of SLN.

Our study showed that risk factors for the FNR were a large tumor size $(\geq 4 \mathrm{~cm})$, LVSI, and microscopic PM invasion in univariate analysis, and only microscopic PM invasion was a significant factor among them by backward elimination for the multivariate analysis. Furthermore, we found that DOI, a previous history of a LEEP and vaginal extension status, were also associated factors for the false-negative detection of SLN. These factors may be associated with the destruction of the lymphatic channel. When injecting ICG into the cervix, it is sometimes difficult to find the injection site if the tumor is bulky. According to Zarganis et al., LVSI and a larger tumor size often affect false-negative detection of SLN and may increase the risk thereof [30]. Salvo et al. also explained that debris or tumor emboli from larger tumors clogging lymphatics might keep mapping substances from reaching nodes [31]. According to Dargent et al.'s study of SNL mapping of cervical cancer patients with radiotracer/blue dye, the history of previous conization was associated with mapping failure [32].

On the other hand, for the cases in which the tumor was smaller than $2 \mathrm{~cm}$, and where both $18 \mathrm{~F}$ FDG PET/CT and MRI showed lymph node negativity, the sensitivity, specificity, and NPV were $100 \%$. This value is similar to that in previous studies $[20,29]$. Another recent retrospective study of SLN biopsy in early cervical cancer showed a high sensitivity of 
Table 6 Logistic regression for risk factors affecting false-negative detection of SLN

\begin{tabular}{|c|c|c|c|c|c|c|}
\hline \multirow[t]{2}{*}{ Characteristics } & \multicolumn{3}{|c|}{ Univariate } & \multicolumn{3}{|c|}{ Stepwise multivariate analysis } \\
\hline & $\mathrm{OR}$ & $95 \% \mathrm{Cl}$ & $P$ & OR & $95 \% \mathrm{Cl}$ & $P$ \\
\hline No previous LEEP & 0.135 & $0.016-1.126$ & 0.0643 & & & \\
\hline Size $\geq 4 \mathrm{~cm}$ & 8.125 & $1.831-36.049$ & 0.0059 & & & \\
\hline LVSI present & 8.674 & $1.675-44.911$ & 0.01 & & & \\
\hline Pathological parametrial invasion & 16.001 & $3.398-75.35$ & 0.0005 & 16.001 & $3.398-75.35$ & 0.0005 \\
\hline Vaginal extension & 4.563 & $0.953-21.851$ & 0.0575 & & & \\
\hline Depth of invasion (cm) & 1.132 & $1-3.444$ & 0.0504 & & & \\
\hline FIGO stage & 1.726 & $0.822-3.623$ & 0.1494 & & & \\
\hline
\end{tabular}

SLN sentinel lymph node, LEEP loop electrosurgical excision procedure, LVSI lymphovascular space invasion, FIGO International Federation of Obstetrics and Gynecology

96.4\% (95\% CI 79.8-99.8\%) and an NPV of $99.3 \%$ (95\% CI 95.6-100\%) [31]. Given our results, it seems that detailed criteria are required for SLN biopsy in early cervical cancer. For example, specifically, the tumor should be less than $2 \mathrm{~cm}$ diameter, and there should be no suspicious lymphadenopathy on imaging tests for best results with SLN mapping with ICG.

The strength of our study is that there were a large number of cases that could be operated from a large tumor size up to stage IIA. And our study is the only one that makes the comparison of the risk factors between the group with false-negative detection of SLN using ICG and that having no false-negative detection of SLN using ICG.

One of the limitations of our study is that it is a retrospective study with a small sample size. We included all patients who underwent SLN biopsy with ICG during this period to minimize the selection bias.

\section{Conclusion}

In conclusion, SLN mapping with ICG in cervical cancer is feasible and has high detection rate. And it may be possible to perform SLN biopsy alone in early-stage cervical cancer when the tumor is less than $2 \mathrm{~cm}$ and lymph node metastasis is not suspected on image examination. However, for large or invasive tumors, we would have to be cautious about performing SLN biopsy alone. Large-scale prospective studies are needed to determine whether SLN biopsy only can be performed in early cervical cancer. Furthermore, a detailed guideline for the SLN biopsy in cervical cancer will need to be established.

\footnotetext{
Abbreviations

18F-FDG PET/CT: 18F-fluoro-deoxyglucose positron emission tomography/ computed tomography; FIGO: International Federation of Gynecology and Obstetrics; FNR: False-negative rate; ICG: Indocyanine green; LEEP: Loop electrosurgical excisional procedure; LVSI: Lymphovascular space invasion; MRI: Magnetic resonance imaging; NPV: Negative predictive value; PM: Parametrial; SLN: Sentinel lymph node
}

Funding

None

\section{Availability of data and materials}

The datasets during and/or analyzed during the current study are available from the corresponfing author on reasonable requests.

\section{Authors' contributions}

D-YK conceived and designed the study. J-HK, D-SS, J-HK, and Y-TK contributed to the acquisition of the data. D-YK, J-HK, and J-HN analyzed and/or interpreted the data. J-HK drafted the manuscript. D-YK and Y-MK revised the manuscript critically for important intellectual content. All authors approved the final version of the manuscript to be published.

\section{Ethics approval and consent to participate}

The study was approved by the Institutional Review Board of the Asan Medical Center (Seoul, Korea IRB number 2017-0600), and all patients provided their informed consent.

\section{Consent for publication}

Not applicable

\section{Competing interests}

The authors declare that they have no competing interests.

\section{Publisher's Note}

Springer Nature remains neutral with regard to jurisdictional claims in published maps and institutional affiliations.

Received: 23 November 2017 Accepted: 14 February 2018

Published online: 09 March 2018

\section{References}

1. Siegel RL, Miller KD, Jemal A. Cancer statistics, 2015. CA Cancer J Clin. 2015; 65:5-29.

2. Lee YH, Choi KS, Lee HY, Jun JK. Current status of the National Cancer Screening Program for Cervical Cancer in Korea, 2009. J Gynecol Oncol. 2012;23:16-21.

3. Jemal A, Bray F, Center MM, Ferlay J, Ward E, Forman D. Global cancer statistics. CA Cancer J Clin. 2011;61:69-90.

4. Pecorelli S, Zigliani L, Odicino F. Revised FIGO staging for carcinoma of the cervix. Int J Gynaecol Obstet. 2009;105:107-8.

5. Biewenga P, van der Velden J, Mol BW, et al. Prognostic model for survival in patients with early stage cervical cancer. Cancer. 2011;117:768-76.

6. Macdonald OK, Chen J, Dodson M, Lee CM, Gaffney DK. Prognostic significance of histology and positive lymph node involvement following radical hysterectomy in carcinoma of the cervix. Am J Clin Oncol. 2009:32:411-6.

7. Kraft O, Sevcik L, Klat J, Koliba P, Curik R, Kriozva H. Detection of sentinel lymph nodes in cervical cancer. A comparison of two protocols. Nucl Med Rev Cent East Eur. 2006;9:65-8. 
8. Fuller AF Jr, Elliott N, Kosloff C, Lewis JL Jr. Lymph node metastases from carcinoma of the cervix, stages IB and IIA: implications for prognosis and treatment. Gynecol Oncol. 1982;13:165-74.

9. Quinn MA, Benedet $J$, Odicino F, et al. Carcinoma of the cervix uteri. FIGO 26th Annual Report on the Results of Treatment in Gynecological Cancer. Int J Gynaecol Obstet. 2006:95(Suppl 1):S43-103.

10. Kim SM, Choi HS, Byun JS. Overall 5-year survival rate and prognostic factors in patients with stage IB and IIA cervical cancer treated by radical hysterectomy and pelvic lymph node dissection. Int J Gynecol Cancer. 2000;10:305-12.

11. Kadkhodayan S, Hasanzadeh M, Treglia G, et al. Sentinel node biopsy for lymph nodal staging of uterine cervix cancer: a systematic review and meta-analysis of the pertinent literature. Eur J Surg Oncol. 2015;41:1-20.

12. Marin F, Plesca M, Bordea Cl, et al. Postoperative surgical complications of lymphadenohysterocolpectomy. J Med Life. 2014;7:60-6.

13. Querleu D, Leblanc E, Cartron G, Narducci F, Ferron G, Martel P. Audit of preoperative and early complications of laparoscopic lymph node dissection in 1000 gynecologic cancer patients. Am J Obstet Gynecol. 2006;195:1287-92

14. Achouri A, Huchon C, Bats AS, Bensaid C, Nos C, Lecuru F. Complications of lymphadenectomy for gynecologic cancer. Eur J Surg Oncol. 2013;39:81-6.

15. Allameh T, Hashemi V, Mohammadizadeh F, Behnamfar F. Sentinel lymph node mapping in early stage of endometrial and cervical cancers. J Res Med Sci. 2015;20:169-73.

16. Hauspy J, Beiner M, Harley I, Ehrlich L, Rasty G, Covens A. Sentinel lymph node in vulvar cancer. Cancer. 2007;110:1015-23.

17. de Hullu JA, Doting E, Piers DA, et al. Sentinel lymph node identification with technetium-99m-labeled nanocolloid in squamous cell cancer of the vulva. J Nucl Med. 1998;39:1381-5.

18. Morton DL, Wen DR, Foshag LJ, Essner R, Cochran A. Intraoperative lymphatic mapping and selective cervical lymphadenectomy for early-stage melanomas of the head and neck. J Clin Oncol. 1993;11:1751-6.

19. Ditto A, Martinelli F, Bogani G, Papadia A, Lorusso D, Raspagliesi F. Sentinel node mapping using hysteroscopic injection of indocyanine green and laparoscopic near-infrared fluorescence imaging in endometrial cancer staging. J Minim Invasive Gynecol. 2015;22:132-3.

20. Lecuru F, Mathevet $P$, Querleu D, et al. Bilateral negative sentinel nodes accurately predict absence of lymph node metastasis in early cervical cancer: results of the SENTICOL study. J Clin Oncol. 2011;29:1686-91.

21. Wuntakal R, Papadopoulos AJ, Montalto SA, Perovic M, Coutts M, Devaja O. Location of sentinel lymph node in cervical carcinoma and factors associated with unilateral detection. Int J Gynecol Cancer. 2015:25:1663-8.

22. Holman LL, Levenback CF, Frumovitz M. Sentinel lymph node evaluation in women with cervical cancer. J Minim Invasive Gynecol. 2014;21:540-5.

23. Rob L, Robova H, Halaska MJ, Hruda M, Skapa P. Current status of sentinel lymph node mapping in the management of cervical cancer. Expert Rev Anticancer Ther. 2013;13:861-70.

24. Fader AN, Edwards RP, Cost M, et al. Sentinel lymph node biopsy in earlystage cervical cancer: utility of intraoperative versus postoperative assessment. Gynecol Oncol. 2008;111:13-7.

25. Park JY, Kim DY, Kim JH, et al. Comparison of outcomes between radical hysterectomy followed by tailored adjuvant therapy versus primary chemoradiation therapy in IB2 and IIA2 cervical cancer. J Gynecol Oncol. 2012;23:226-34

26. Connolly JL. Changes and problematic areas in interpretation of the AJCC Cancer Staging Manual, 6th Edition, for breast cancer. Arch Pathol Lab Med. 2006:130:287-91.

27. Buda A, Crivellaro C, Elisei F, et al. Impact of indocyanine green for sentinel lymph node mapping in early stage endometrial and cervical cancer: comparison with conventional radiotracer $(99 \mathrm{~m}) \mathrm{tc}$ and/or blue dye. Ann Surg Oncol. 2016:23:2183-91.

28. Beavis AL, Salazar-Marioni S, Sinno AK, et al. Sentinel lymph node detection rates using indocyanine green in women with early-stage cervical cancer. Gynecol Oncol. 2016;143:302-6.

29. Tax C, Rovers MM, de Graaf C, Zusterzeel PL, Bekkers RL. The sentinel node procedure in early stage cervical cancer, taking the next step: a diagnostic review. Gynecol Oncol. 2015;139:559-67.

30. Zarganis $P$, Kondi-Pafiti A, Arapantoni-Dadioti $P$, et al. The sentinel node in cervical cancer patients: role of tumor size and invasion of lymphatic vascular space. In Vivo. 2009;23:469-73.
31. Salvo G, Ramirez PT, Levenback CF, et al. Sensitivity and negative predictive value for sentinel lymph node biopsy in women with early-stage cervical cancer. Gynecol Oncol. 2017;145:96-101.

32. Dargent D, Enria R. Laparoscopic assessment of the sentinel lymph nodes in early cervical cancer. Technique--preliminary results and future developments. Crit Rev Oncol Hematol. 2003:48:305-10.

\section{Submit your next manuscript to BioMed Central and we will help you at every step:}

- We accept pre-submission inquiries

- Our selector tool helps you to find the most relevant journal

- We provide round the clock customer support

- Convenient online submission

- Thorough peer review

- Inclusion in PubMed and all major indexing services

- Maximum visibility for your research

Submit your manuscript at www.biomedcentral.com/submit
Biomed Central 